\title{
Malignant tracheoesophageal fistula: diagnosis and management
}

\author{
Jahnavi Kakuturu, Ankit Dhamija, Alper Toker \\ Department of Cardiovascular and Thoracic Surgery, West Virginia University School of Medicine, Morgantown, WV, USA \\ Contributions: (I) Conception and design: J Kakuturu, A Toker; (II) Administrative support: None; (III) Provision of study materials or patients: None; \\ (IV) Collection and assembly of data: All authors; (V) Data analysis and interpretation: J Kakuturu, A Toker; (VI) Manuscript writing: All authors; (VII) \\ Final approval of manuscript: All authors. \\ Correspondence to: Alper Toker, MD. Department of Cardiovascular and Thoracic Surgery, West Virginia University School of Medicine, 1 Medical \\ Center Drive, Box 8500, Morgantown, WV, USA. Email: salpertoker@gmail.com.
}

\begin{abstract}
Tracheoesophageal fistula (TEF) refers to a pathological connection between the tracheobronchial tree and esophagus, and may be found in 5-15\% of esophageal and 1\% of tracheo-bronchial malignancies. Individuals with such advanced malignancy resulting in TEF, are usually at terminal stages of disease. They are often burdened with intolerance to feeding and are subject to frequent pulmonary infections secondary to respiratory contamination. Presentation varies from mild coughing to florid sepsis due to aspiration pneumonia. Diagnosis can usually be made by bronchoscopy and esophagoscopy. In cases where the TEF is small and cannot be visualized by these methods, fluoroscopic swallow evaluation may be useful. The primary aims of treatment are to initiate broad spectrum antibiotics when sepsis is present, to separate the esophagus from the respiratory tree preventing soilage, and to ensure enteral nutrition. In order to determine the approach to management, patients may be categorized into those who present with TEF without a diagnosis of a malignancy, those who present with TEF during oncological treatment with chemotherapy and/or radiation, and those in remission after treatment with definitive chemotherapy and/or radiation, and have developed TEF as a complication. The mainstay of therapy is endoscopic stenting of the esophagus and/or airway. Definitive surgical intervention is usually reserved for patients who are tumor free and involves take-down of the fistula with interposition of a muscle flap. Although therapy is mainly palliative in most circumstances, a systematic approach to this disease may provide patients with a better quality of life.
\end{abstract}

Keywords: Malignancy; esophageal stent; tracheoesophageal fistula (TEF); airway stent

Received: 11 February 2021; Accepted: 13 July 2021; Published: 25 August 2022.

doi: $10.21037 /$ ccts-21-8

View this article at: https://dx.doi.org/10.21037/ccts-21-8

\section{Introduction}

Tracheoesophageal fistula (TEF) refers to a pathological connection between the tracheo-bronchial tree and esophagus, which may be congenital or acquired in nature. Although the term refers mainly to a communication with the trachea, TEFs can also include fistulas to the major or minor bronchi, or peripheral pulmonary parenchyma. In adults, TEFs are more commonly acquired, secondary to trauma, prolonged endotracheal intubation, iatrogenic injury, or malignancy, predominantly esophageal or bronchogenic carcinoma (1). Between $5-15 \%$ of patients with esophageal cancer may develop TEFs, while it is only observed in less than $1 \%$ of patients with primary airway malignancies $(2,3)$. With esophageal cancers, squamous cell carcinoma is more commonly associated with TEFs, compared to adenocarcinoma $(4,5)$. Individuals with advanced malignant disease resulting in TEFs, have decreased survival, are often burdened with intolerance to feeding, and are subject to frequent pulmonary infections secondary to respiratory contamination. Both portend to a poor quality of life (4). Treatment options are mainly palliative. They have evolved from permanent esophageal intubation, esophageal bypass, esophageal exclusion with esophagostomy and gastrostomy, to currently include the placement of esophageal and/or airway stents in the 
majority of cases $(6,7)$.

\section{Pathogenesis}

Several mechanisms for the development of TEFs have been described (8). Most commonly, given the proximity of the esophagus to the trachea and left main stem bronchus, there may be direct invasion of the tumor from one structure to the other. The thin layer of intervening loose areolar tissue provides little resistance to infiltration by the tumor and may lead to ulceration of the membranous trachea or esophageal lumen, and subsequent TEF formation. This process is augmented in patients receiving chemotherapy and/or radiation which may result in tumor necrosis followed by fistulization. In fact, a recent study reported that TEFs related to prior treatment for esophageal carcinoma are more common than TEFs caused by direct invasion of the tumor (4). Another theory involves spread to mediastinal nodes, which are the primary sites of lymphatic drainage in both esophageal and lung cancer. Once there is tumor involvement of these nodes, predominantly those in the subcarinal space, they may adhere to and erode into the esophagus and trachea, resulting in a TEF. Rarely, mediastinal lymphomas may produce a TEF in this manner (9).

Additionally, in advanced esophageal or tracheal cancers, treatment modalities used for relief of obstruction may cause TEF formation. Endoscopic dilation of a malignant stricture complicated by inadvertent perforation, may lead to mediastinal sepsis with possible fistulization. Ironically, although stents are widely used in the management of TEFs, stenting for palliation in obstructive airway or esophageal tumors, can result in pressure necrosis, eroding through the luminal wall and thus resulting in a TEF. The reported incidence for stent-associated TEFs is approximately $4 \%$ and is most commonly seen with mid esophageal lesions (10). Furthermore, TEFs may also develop as a complication after esophagectomy. Risk factors include injury to the trachea or bronchi during mediastinal dissection and post-operative esophageal anastomotic leak with a mediastinal abscess (8).

\section{Clinical features and diagnosis}

Symptoms may vary depending on the location of the primary tumor but commonly include cough (56\%), recurrent aspiration (37\%), fever (25\%), and dysphagia (19\%) (6). Physical examination may reveal cachexia, hoarseness, and stridor (8). In cases of recurrent aspiration leading to pneumonia, patients may develop florid sepsis, and present in extremis.

Historically, a diagnosis of TEF was made if a barium or Gastrografin swallow unexpectedly outlined the airways. In recent years, the planned diagnostic approach has been flexible bronchoscopy, followed by esophagoscopy. If malignancy has not been previously confirmed, a biopsy is performed for pathological diagnosis. TEFs located in the posterior wall of the trachea can usually be identified by esophagoscopy. However, the location, size, and appearance of TEFs can vary widely in different patients, and standard diagnostic guidelines may not be applicable to every case. Furthermore, very small fistulas can be overlooked if the mucosa is erythematous and inflamed, without evidence of an opening. In these circumstances, fluoroscopic swallow evaluation may be beneficial in confirming or eliminating the diagnosis of TEF. Another adjunct which may assist in identification of smaller fistulas, is oral intake of methylene blue, followed by bronchoscopic evaluation (7). Computed tomography (CT) scanning combined with three-dimensional reconstruction may also be useful in delineating the extent of the of the tumor and involvement of surrounding structures.

The middle-third of the esophagus is predominantly involved in TEFs while the site of respiratory communication is tracheal in the majority of cases (52-57\%), followed by a bronchial location (37-40\%), and less commonly to lung parenchyma $(3-11 \%)(2,11)$. Categorization of TEFs based on their location in the airway, has been suggested but application to clinical practice has been limited. Wang et al. developed a comprehensive TEF classification system based on an existing classification for central airway stenosis $(12,13)$. The proposed system includes eight zones based on fistula location. Locations I-III are the same as the categories used for central airway stenosis, where the TEF involves the upper, middle and lower thirds of the trachea, respectively. Zone IV-VIII comprise of the carina (IV), right mainstem bronchus $(\mathrm{V})$, right middle bronchus (VI), proximal left main bronchus (VII), and distal left main bronchus (VIII).

\section{Management}

\section{General considerations}

Management of malignant TEFs is particularly challenging since these pathologies usually develop at the preterminal 
stage. Patients deteriorate very rapidly due to soiling of the respiratory tree by oral and gastric secretions. The cause of death is generally pneumonia and sepsis, rather than the underlying cancer. The primary aims of treatment are to separate the esophagus from the respiratory tree preventing soilage, and to ensure enteral nutrition through resumption of oral intake or providing alternative means, such as a gastrotomy or jejunostomy. Leaving a patient in discontinuity, with an esophagostomy and gastrostomy or using intestinal or colonic conduits, has been attempted but is fraught with high morbidity and mortality rates $(14,15)$.

Initial therapy will depend on the clinical presentation. Oral intake should be restricted, with intravenous (IV) fluids to correct dehydration and electrolyte abnormalities. Additionally, the head of the bed should be kept elevated, in an effort to reduce aspiration risk. Patients with recurrent episodes of aspiration, who present with pneumonia and sepsis will necessitate IV antibiotics.

To assist in describing the approach for TEFs, it is helpful to create subgroups. These groups are constructed based on clinical presentation and whether or not the patient has received prior treatment for the underlying malignancy, and are as follows.

(I) Patients who present with TEF findings without a diagnosis of a malignancy.

(II) Patients who present with a TEF during oncological treatment with chemotherapy and/or radiation.

(III) Patients treated with definitive chemotherapy and/or radiation and have developed a TEF as a complication of treatment. These patients are in complete remission, and are subcategorized into,

i. Those with pneumonia and septic findings.

ii. Those without infectious findings.

\section{Patients who present with TEF findings without a diagnosis of a malignancy}

In such patients, immediate bronchoscopy and esophagoscopy will reveal the diagnosis. If endotracheal (ET) intubation is required for respiratory deterioration, the cuff of the ET tube should be inflated distal to the TEF site, if possible. Since the underlying problem is advanced malignancy, patients are likely to have poor nutritional status and need to be optimized prior to intervention. Treatment is usually palliative and directed at improving quality of life during the remaining few months of survival. If the general condition of the patient can be improved to a level that chemotherapy and/or radiation would be an option, then the primary aim is to restore oral intake or institute feeding via gastrostomy or jejunostomy. If the fistula is in a cervical location, close to the cricoid and laryngeal apparatus, a primary tracheal tumor is likely and a tracheostomy with a percutaneous endoscopic gastrostomy (PEG) tube would be preferred over stenting. If, however, a primary cervical esophageal tumor is infiltrating the trachea, esophageal obstruction may preclude PEG tube insertion. Under these circumstances, surgically or radiologically guided jejunostomy tube insertion may be required, in conjunction with a tracheostomy below the level of fistula.

\section{Patients who present with a TEF during oncological treatment with chemotherapy and/or radiation}

In this population, the general condition of the patient is often poor and vulnerable to infection and sepsis. Management should include fluid resuscitation, and institution of antibiotics, as indicated. If the location of the tumor is suitable, the best option is to place an esophageal stent (details given below). Tracheal stenting or combined tracheal and esophageal stenting may also be an option (Figure 1). The preferred approach at our institution (WVU) is esophageal stenting. Follow up endoscopy with modification of stents and endoluminal treatment options such as a cryotherapy are often performed.

\section{Patients treated with definitive chemotherapy and/ or radiation and have developed TEF as result of treatment}

Patients in complete remission who develop TEF as a complication of treatment, may present with either findings of sepsis, or with signs of early aspiration without sepsis. If the patient is non-toxic on admission, and without overt evidence of aspiration, they may be considered for surgical resection. This decision is carefully deliberated, since prior treatment with high dose radiation, increases the rate of complications when operating on the trachea. In experienced centers, the primary surgical approach involves division of the fistulous tract with interposition of a muscle flap between the esophagus and airway. If the patient is septic on presentation, we primarily treat the infection and prevent soilage of the lungs, with esophageal stenting, if feasible (Figure 2). Surgical correction is then reconsidered after resolution of TEF complications.

\section{Endoscopic stenting}

Types of esophageal stents have shown significant advancement over the last few decades. The technique 

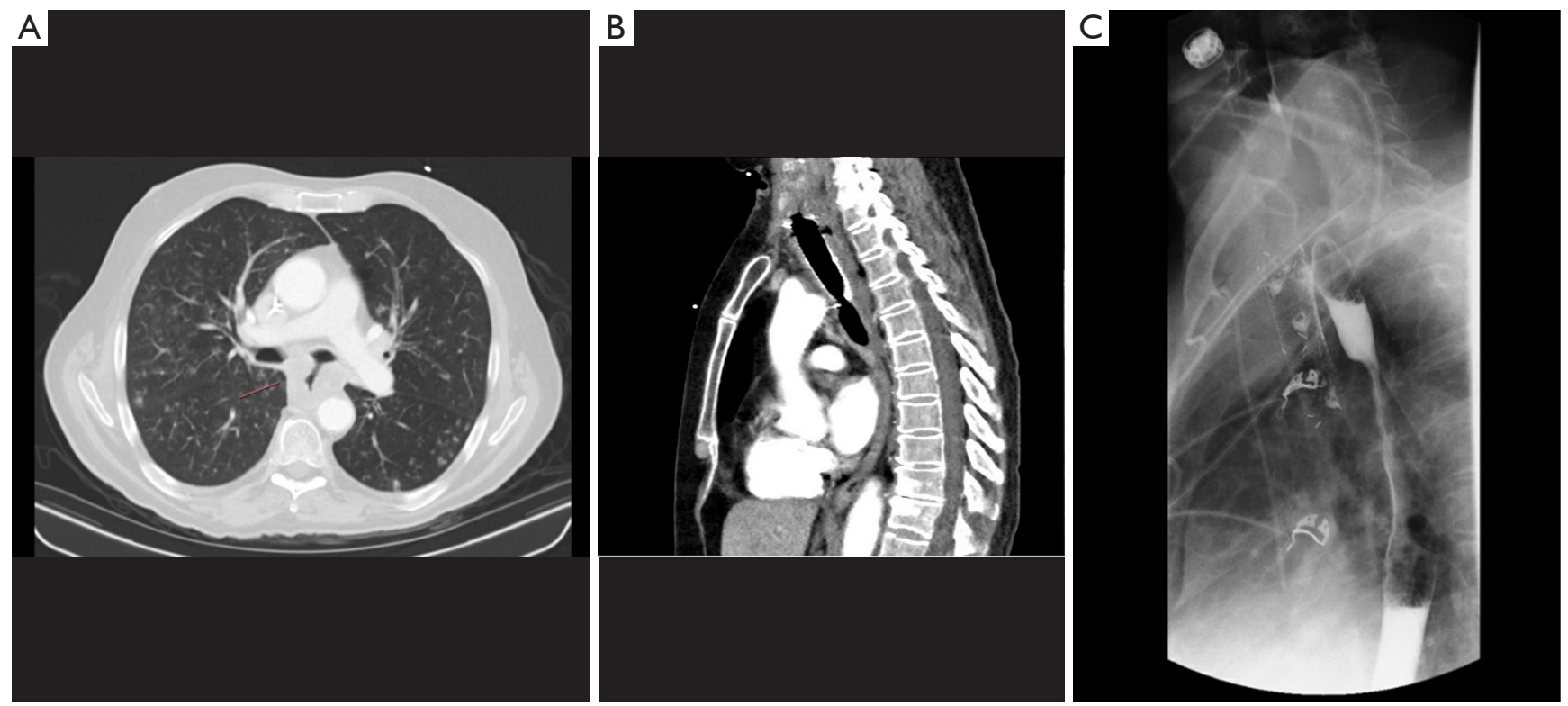

Figure 1 Primary esophageal cancer infiltrating the left main bronchus (A). This patient was diagnosed with a TEF during oncological treatment. He was stented first with an esophageal stent and re-stented with covered airway stents of the trachea and left main stem bronchus (B,C). He was treated with immunotherapy and was still alive after one year. TEF, tracheoesophageal fistula.
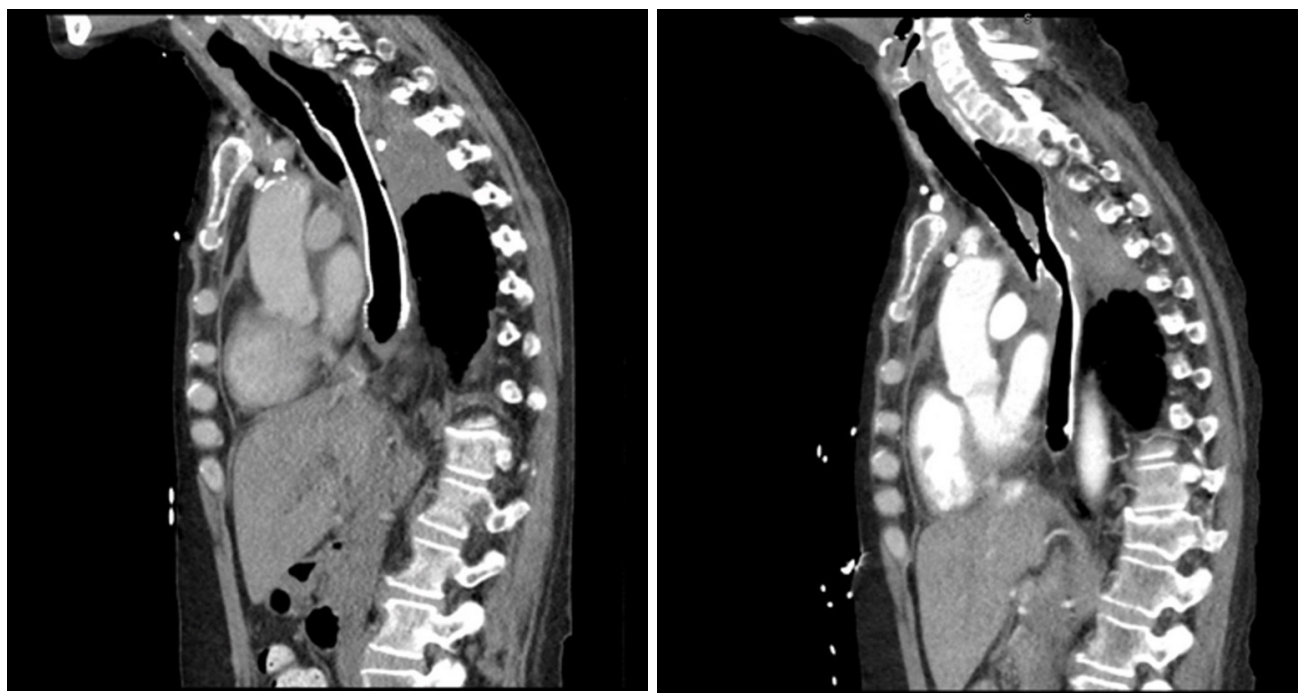

Figure 2 Patient with small cell lung cancer treated 10 years prior. She developed an esophageal stricture after radiation, requiring multiple dilations, which was subsequently complicated by TEF formation just above the carina. CT scan showed aspiration pneumonia and the patient was treated with an esophageal stent (shown above). Once her parenchymal findings improved, she was scheduled for definitive surgical repair of the TEF. TEF, tracheoesophageal fistula.

initially involved permanent esophageal intubation with a Mousseau-Barbin or Celestin tube combined with gastrostomy (16). These procedures were done operatively and associated with high mortality rates. Coated self- expanding metallic stents (SEMS) were then introduced with high success rates $(2,17)$. Stents may be deployed in the esophagus, airway, or sometimes concomitantly in both locations (18). Esophageal stents are available as partially 
or fully covered SEMS, while airway stents maybe covered SEMS or silicone stents. In most cases, esophageal stents are placed first, since the tumor is more likely esophageal, causing obstruction, and fistulization. The technique involves endoscopy and passage of a guidewires across the segment with the TEF, which in most cases may also be stenotic due to the malignancy. The required length and diameter of the stent is then measured to accurately cover the TEF (at least $2 \mathrm{~cm}$ of healthy mucosa proximal and distal to the TEF), and the stent deployed, usually under fluoroscopic guidance (3). A contrast study is performed after stent deployment to verify that the fistula has been closed. In the event of a proximal TEF, close to the upper esophageal sphincter, or complete obstruction of the esophageal lumen precluding passage of a guidewire, esophageal stenting may not be possible, and an airway stent may be primarily used in this situation.

Although our practice is to first place an esophageal stent whenever possible, some authors do not recommend primary esophageal stenting, due to potential compression of the trachea resulting in suffocation (19). For this reason, they recommend use of double stents, with the tracheal stent implantation preceding esophageal stenting. Other indications for double stenting include stenosis of both the esophageal and tracheal lumen in addition to the TEF, or in cases of very large TEFs with persistent leakage of contrast after esophageal stent insertion (3). If the carina is involved, a Y-stent may be required. Yamamoto and colleagues reported on 11 patients who underwent successful double stenting with significant improvement of both dyspnea and dysphagia (20). TEFs were successfully closed in all except one patient, who was on mechanical ventilation. Another study prospectively assessed stent location and survival in 112 patients with malignant TEFs (21). The mean survival for airway stents $(\mathrm{n}=65)$, esophageal stents $(\mathrm{n}=37)$, and double stents $(\mathrm{n}=10)$ was 219 days, 263 days, and 253 days, respectively. Although the authors of this study preferentially used tracheal stents, the data implies that airway stenting may be associated with decreased survival. As such, we do not recommend airway stenting as the preferred approach. Complications associated with stenting include bleeding, stent migration (more likely with uncovered stents), food impaction, and enlargement of the TEF (especially with use of double stents).

Degradable stents have recently been introduced in the market and may be employed when permanent covering of a fistula is not required. They usually have a lower radial force and are generally uncovered. Another endoscopic technique utilized for TEF management is the OTSC system (Ovesco Endoscopy GmbH, Tubingen, Germany), which was originally introduced for the closure of gastrointestinal defects (19). It consists of a nitinol clip, attached to an applicator integrated onto the tip of an endoscope. Good outcomes have been reported with its use in the management of TEFs $(22,23)$.

\section{Surgical interventions}

Prior to the advent of modern SEMS, surgery was usually performed to exclude the fistula, and to restore orogastric continuity for feeding (5). Techniques for achieving these goals involve concomitant gastrostomy and tracheostomy, or exclusion of the TEF site, combined with bypass using a gastric pull-up or colonic interposition (16). These procedures are fraught with complications especially in the cachectic cancer patient and are now rarely performed. In patients with malignant TEFs, esophagectomy is associated with high morbidity and mortality rates of $40 \%$ and $14 \%$, respectively, and should therefore be considered only in select patients (24). Surgical intervention remains an option in patients who are tumor free. In our experience, we preferentially close the fistula without major tracheal resection, primarily close the esophageal wall, and transpose muscle in between the esophagus and trachea. If the esophageal wall cannot be closed primarily, a gastric conduit may be created to form a neoesophagus. A post-operative esophagogram is obtained, and the patient is started on a liquid diet thereafter (Figure 3). It is of utmost importance that patients being considered for reconstruction be carefully selected, and any major surgical intervention be reserved for those who have completely recovered from the primary malignancy.

\section{Conclusions}

Several therapeutic options are available for the management of malignant TEFs, such that it should no longer be considered a terminal diagnosis. Current endoscopic techniques, surgical approaches, and oncological treatments are associated with better outcomes, compared to published series in the last decade. The patient with a malignant TEF should be approached systematically, based on the location of TEF, and the stage at which the TEF is diagnosed. Multiple treatment options exist, and outcomes of these approaches are awaited. Although therapy may be palliative in most circumstances, a systematic approach to this disease may 


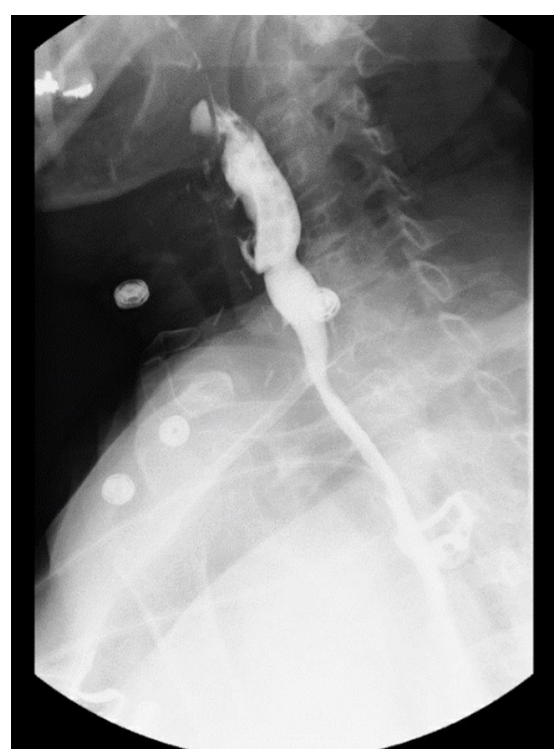

Figure 3 Post-operative esophagogram of a TEF treated surgically. 62-year-old female with tracheal cancer treated with chemotherapy and radiation, developed a TEF post-treatment. She had a temporary tracheal stent placed, which was later found to be fractured distally. Patient complained of shortness of breath and subsequently underwent bronchoscopy, left neck exploration, tracheal stent removal, repair of tracheoesophageal fistula, closure of the tracheal defect (3-0 PDS), mobilization of the sternohyoid for coverage of the tracheal repair, and esophageal repair (4-0 PDS). Post-operative esophagogram showed no evidence of TEF and no strictures of the esophagus. TEF, tracheoesophageal fistula.

provide patients with a better quality of life.

\section{Acknowledgments}

Funding: None.

\section{Footnote}

Provenance and Peer Review: This article was commissioned by the Guest Editor (Tutku Soyer) for the series "Tracheoesophageal Fistula" published in Current Challenges in Thoracic Surgery. The article has undergone external peer review.

Conflicts of Interest: All authors have completed the ICMJE uniform disclosure form (available at https://ccts. amegroups.com/article/view/10.21037/ccts-21-8/coif). The series "Tracheoesophageal Fistula" was commissioned by the editorial office without any funding or sponsorship. The authors have no other conflicts of interest to declare.

Ethical Statement: The authors are accountable for all aspects of the work in ensuring that questions related to the accuracy or integrity of any part of the work are appropriately investigated and resolved.

Open Access Statement: This is an Open Access article distributed in accordance with the Creative Commons Attribution-NonCommercial-NoDerivs 4.0 International License (CC BY-NC-ND 4.0), which permits the noncommercial replication and distribution of the article with the strict proviso that no changes or edits are made and the original work is properly cited (including links to both the formal publication through the relevant DOI and the license). See: https://creativecommons.org/licenses/by-nc-nd/4.0/.

\section{References}

1. Reed MF, Mathisen DJ. Tracheoesophageal fistula. Chest Surg Clin N Am 2003;13:271-89.

2. Balazs A, Kupcsulik PK, Galambos Z. Esophagorespiratory fistulas of tumorous origin. Non-operative management of 264 cases in a 20-year period. Eur J Cardiothorac Surg 2008;34:1103-7.

3. Hürtgen M, Herber SCA. Treatment of malignant tracheoesophageal fistula. Thorac Surg Clin 2014;24:117-27.

4. Goh KJ, Lee P, Foo AZX, et al. Characteristics and Outcomes of Airway Involvement in Esophageal Cancer. Ann Thorac Surg 2021;112:912-20.

5. Lolley DM, Ray JF, Ransdell HT, et al. Management of malignant esophagorespiratory fistula. Ann Thorac Surg 1978;25:516-20.

6. Burt M, Diehl W, Martini N, et al. Malignant esophagorespiratory fistula: management options and survival. Ann Thorac Surg 1991;52:1222-8; discussion 1228-9.

7. Ke $\mathrm{M}, \mathrm{Wu} \mathrm{X}$, Zeng J. The treatment strategy for tracheoesophageal fistula. J Thorac Dis 2015;7:S389-97.

8. Shamji FM, Inculet R. Management of Malignant Tracheoesophageal Fistula. Thorac Surg Clin 2018;28:393-402.

9. Moree JS, Bhakta MG, Ledbetter J. Complication of mediastinal mass: acquired tracheoesophageal fistula associated with T-cell lymphoblastic lymphoma. Pediatr 
Pulmonol 2006;41:688-9.

10. Bick BL, Song LM, Buttar NS, et al. Stent-associated esophagorespiratory fistulas: incidence and risk factors. Gastrointest Endosc 2013;77:181-9.

11. Duranceau A, Jamieson GG. Malignant tracheoesophageal fistula. Ann Thorac Surg 1984;37:346-54.

12. Wang H, Tao M, Zhang N, et al. Airway Covered Metallic Stent Based on Different Fistula Location and Size in Malignant Tracheoesophageal Fistula. Am J Med Sci 2015;350:364-8.

13. Freitag L, Ernst A, Unger M, et al. A proposed classification system of central airway stenosis. Eur Respir J 2007;30:7-12.

14. Irving JD, Simson JN. A new cuffed oesophageal prosthesis for the management of malignant oesophagorespiratory fistula. Ann R Coll Surg Engl 1988;70:13-5.

15. Sargeant IR, Thorpe S, Bown SG. Cuffed esophageal prosthesis: a useful device in desperate situations in esophageal malignancy. Gastrointest Endosc 1992;38:669-75.

16. Symbas PN, McKeown PP, Hatcher CR Jr, et al. Tracheoesophageal fistula from carcinoma of the esophagus. Ann Thorac Surg 1984;38:382-6.

17. Low DE. Keeping an open mind while restoring esophageal patency in patients with cancer and esophagorespiratory fistula. Ann Thorac Surg

doi: $10.21037 /$ ccts-21-8

Cite this article as: Kakuturu J, Dhamija A, Toker A. Malignant tracheoesophageal fistula: diagnosis and management. Curr Chall Thorac Surg 2022;4:29.
1996;62:961-2.

18. Nasir BS, Tahiri M, Kazakov J, et al. Palliation of Concomitant Tracheobronchial and Esophageal Disease Using a Combined Airway and Esophageal Approach. Ann Thorac Surg 2016;102:400-6.

19. Zhou C, Hu Y, Xiao Y, et al. Current treatment of tracheoesophageal fistula. Ther Adv Respir Dis 2017;11:173-80.

20. Yamamoto R, Tada H, Kishi A, et al. Double stent for malignant combined esophago-airway lesions. Jpn J Thorac Cardiovasc Surg 2002;50:1-5.

21. Herth FJ, Peter S, Baty F, et al. Combined airway and oesophageal stenting in malignant airway-oesophageal fistulas: a prospective study. Eur Respir J 2010;36:1370-4.

22. Traina M, Curcio G, Tarantino I, et al. New endoscopic over-the-scope clip system for closure of a chronic tracheoesophageal fistula. Endoscopy 2010;42 Suppl 2:E54-5.

23. Vinnamala S, Murthy B, Parmar J, et al. Rendezvous technique using bronchoscopy and gastroscopy to close a tracheoesophageal fistula by placement of an over-thescope clip. Endoscopy 2014;46 Suppl 1 UCTN:E301.

24. Davydov M, Stilidi I, Bokhyan V, et al. Surgical treatment of esophageal carcinoma complicated by fistulas. Eur J Cardiothorac Surg 2001;20:405-8. 